
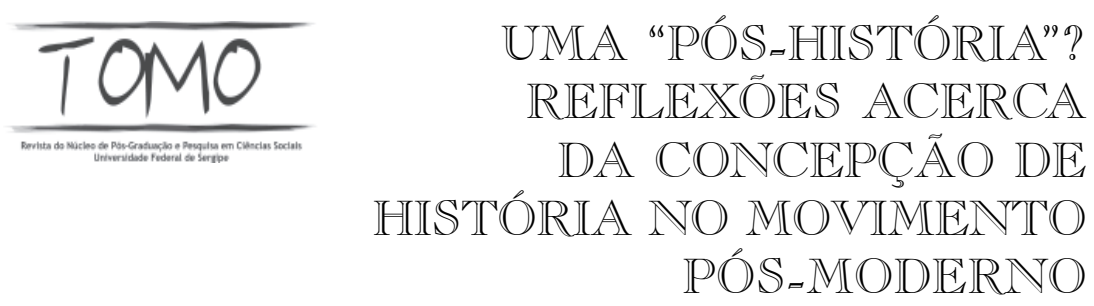

Sandra Damasceno da Rocha

"O que é novo é a inédita consciência surgida na 'posthistoire': o sentimento grassante que vamos ficar para sempre no presente e ao mesmo tempo depois dele” (Heller, A.e Fehér, F.)

diagnóstico de "crise" é um recurso que fica cada vez mais
valioso na teoria social tanto mais se invista em sensacionalismos e inovações vazias. Ele foi incorporado em diversos momentos do desenvolvimento das Ciências Sociais e foi visto não apenas enquanto um mero processo de ruptura epistemológica, mas também enquanto um dado intrínseco à própria realidade social, baseando-se na idéia de que a sociedade é confrontada por questões produzidas pelo seu próprio ordenamento e que desafiam os pilares fundamentais do sistema social como um todo. Contemporaneamente, e com uma intensidade vista em poucos momentos da história, um efeito de "crise generalizada" está na ordem do dia na produção do conhecimento sociológico. Fala-se usualmente em crise paradigmática, de identidades, de valores e, até mesmo, de uma crise na própria história ou da sociologia enquanto discurso científico.

* Mestre em Ciências Sociais pela Universidade Federal do Rio Grande do Norte

\begin{tabular}{|l|ll|l|l|} 
TOMO & São & Cristóvão-SE & № 10 & jan./jun. 2007 \\
\hline
\end{tabular}


Esta noção é associada a um processo mais amplo de mudança, que está deslocando as estruturas e processos centrais das sociedades modernas e abalando o quadro de referência que davam aos indivíduos uma ancoragem estável no mundo social.

Conseqüentemente, de sua forma mais intransigente à sua forma mais branda, a idéia de modernidade, enquanto destruição das ordens antigas e triunfo da racionalidade, objetiva ou instrumental, vem cada vez mais sendo questionada no pensamento social contemporâneo. O espírito iluminista, no qual o indivíduo estava estreitamente associado à razão, à liberdade e ao rigor do pensamento, parece desmoronar junto com as tentativas de construção de sociedades que se quiseram igualitárias e justas, na medida em que nem o socialismo burocrático-autoritário nem o capitalismo "vitorioso" cumpriram suas promessas.

Neste sentido, o contexto teórico contemporâneo revela um mal-estar e fala-nos da obsolescência de instrumentos de análise que eram centrais na interpretação da realidade social. Essa dificuldade analítica é denunciada nas tentativas de nomear a sociedade contemporânea com conceitos antepostos de um "pós” ou “des”, como uma alternativa para encontrar em um "outro tempo" as respostas ou os parâmetros para identificar os problemas de "nosso tempo".

Ao discutir acerca da instituição da história no movimento intelectual pósmoderno, o presente texto não tratará de nenhum tema original no pensamento social, na medida em que as tentativas de compreensão dos processos históricos foram as bases de formação e transformação da teoria sociológica. Por sua vez, ele procurará ter sua originalidade apenas (e para nós é mais que suficiente) no que toca à interpretação e à articulação de algumas categorias e definições do pós-modernismo, responsáveis pela leitura dos processos históricos que se reorganizam, ou melhor, que desorganizam os alicerces construídos até então pelas ciências sociais. Uma objeção bastante provável, em especial por parte dos pós-modernos, é a de que estamos tentando conciliar "núcleos conceituais modernos" (como a noção de história) a categorias “pós-modernas”, tentando ler estas últimas com as lentes de uma ciência, e seus instrumentos de análise, em crise no que toca ao seu poder heurístico.

Ora, trabalhar a instituição da história, qualquer que seja a perspectiva de análise ("pós”, “des”, "hiper”, “alta” modernidade ou o que for), implica 
definir qual a visão dos autores em relação aos fundamentos da estrutura e da dinâmica sociais, definindo, por conseqüência, quais as reais capacidades e possibilidades de intervenção dos indivíduos no curso das mudanças. O cientista social que não tiver a preocupação acerca destes fundamentos, não tem qualquer capacidade de interpretar historicamente os fenômenos sociais e, portanto, acaba caindo em uma "sociologia sem sociedade" e sem historicidade, perdendo, por conseguinte, o estatuto de teoria social.

Mas a questão parece que não foi resolvida de forma tão simples: alguns cientistas, por mais absurdo que pareça, colocaram de lado estas preocupações com a estrutura e dinâmica sociais, só que não apenas perderam o estatuto de análise sociológica, como também tornaram-se quase que hegemônicos neste ramo do conhecimento, festejados como os sujeitos de uma "revolução do indivíduo, do local e da linguagem”. Neste contexto, como ficam as análises históricas dos fenômenos sociais se, como que por um decreto, as bases de dinâmica não atendem a nenhum fundamento, se os fenômenos flutuam sem rumo e sem qualquer materialidade acima do corpo social e se os indivíduos são destituídos de qualquer referente que lhes permita olhar acima de suas necessidades imediatas?

O que parecia ser um retrocesso surge no palco das ciências sociais como o grande desafio contemporâneo, blindado contra qualquer crítica, na medida em que a crítica é, antes de qualquer coisa, uma construção moderna determinista, racionalista e que não tem mais espaço na teoria social $^{1}$. Não nos resta mais nada senão tentar sistematizar e discutir, sumariamente, seus princípios dissolvidos em textos de difícil compreensão e coerência interna, captando os fundamentos que levam a teoria pós-moderna a negar qualquer possibilidade de se ter uma visão integrada dos fenômenos no conjunto da história (mesmo que não linear como em Weber) e a descartar a necessidade de se pensar a história como um processo sócio-temporal com nexos causais inteligíveis ${ }^{2}$.

Na verdade, a única ação crítica válida é a crítica aos fundamentos modernos. O resto, para eles, é o que sobrou da modernidade agonizando em seu fim.

2 Este abandono da necessidade de uma investigação baseada em nexos históricos causais estruturais seria, sumariamente, a idéia básica do conceito de "pós-história" ("post histoire") tendo como referência central o trabalho de Agnes Heller em A condição política pósmoderna. O termo foi introduzido, mesmo com significado diferente, pelo físico Cournot no séc. XIX (BODEI, Remo, 2001). 


\section{O período "pós-histórico"}

A modernidade emerge da necessidade de se delinear objetivamente os elementos constitutivos essenciais da história, a fim de livrar-se das explicações sacras e mistificadoras dos fenômenos, secularizando o pensamento e redescobrindo a capacidade do homem de se colocar enquanto célula fundante da sociedade (por contrato, submissão ou lei natural) e, por conseqüência, articulador de seu desenvolvimento histórico.

Contudo, no processo de formação da sociologia, essa disciplina ofereceu uma explicação crítica em relação ao individualismo racional dessa concepção de homem. Ela localizou o indivíduo do Iluminismo em processos de grupos e em normas coletivas as quais, argumentavam, subjaziam a qualquer contrato entre sujeitos individuais. Em conseqüência, desenvolveu uma explicação alternativa do modo como os indivíduos são formados subjetivamente através da sua participação em relações sociais mais amplas e, dialeticamente, como os processos e as estruturas sociais são sustentados pelos papéis que os indivíduos neles desempenham. Assim, o processo de "internalização do exterior", no indivíduo, e de conseqüente "externalização do interior" no social, permitiu ao pensamento social ver o desenvolvimento histórico como indissociável da estrutura social e dos processos e relações que a compõem. A análise de qualquer fenômeno social só poderia partir das seguintes perguntas: Qual a sua natureza histórica? Quais são os determinantes causais estruturais? Que orientação estrutural condicionou a ação dos indivíduos envolvidos?

Na visão "anti-estrutural" pós-moderna, estas questões iniciais não fazem mais sentido. Os fenômenos desprendem-se do contexto histórico, e os únicos fundamentos para a interpretação são meramente morais ou estéticos (ou seja, subjetivos). Não há qualquer força estrutural que dê aos fatos formas ou significados sociais. A relação entre o social e o homem, entre a estrutura e o indivíduo, desloca-se para o outro extremo.

Verifica-se, em primeiro lugar, a erosão dos princípios filosóficos que haviam sido erguidos no começo do século XVII. A ontologia, ou seja, a concepção baseada na filosofia clássica de que no corpo social existiriam "estruturas estáveis" - que só não eram claramente perceptí- 
veis porque o homem, no seu processo social, estaria encoberto por uma nuvem de alienação, provocada originalmente pelo processo de trabalho - assim como a metafísica -foram minadas por movimentos filosóficos que defendiam a necessidade de empreender uma espécie de "resgate da filosofia”. Esse resgate teria que criar as bases de uma filosofia desprovida dos princípios metafísicos hegelianos que, incorporados pela tradição marxista, frustraram a capacidade de se ter uma visão lúcida da realidade social a partir de uma concepção de totalidade. Neste sentido, uma impressão política transfigura-se em um pressuposto filosófico: se não há mais possibilidade de se empreender com eficiência projetos políticos grandiosos é porque a realidade social, para os pós-modernos, parece ser mais fragmentada e desconexa do que pensou a filosofia que os antecedeu.

Para esses pensadores, a incapacidade da tradição filosófica hegeliana foi revelada pela própria forma da técnica de auto-impor-se no social. $\mathrm{O}$ desenvolvimento tecnológico foi tornando cada vez mais débil qualquer tipo de "retaguarda filosófica" na medida em que se justificava por si mesmo, prescindindo de uma sombra religiosa, ideológica ou abstrata. Quanto mais se desenvolviam a ciência e a técnica, menos se poderia dizer que elas deveriam se basear num estatuto externo a elas. É por isso que o desenvolvimento técnico acabou por suprimir, especialmente no pós-guerra, o respaldo que se baseava numa filosofia especulativa, num agir ético-político, passando a uma legitimação em si mesmo, segundo seus próprios parâmetros.

O grande problema foi que as crises históricas e os caminhos desastrosos a que conduziram os desenvolvimentos técnicos e as tecnologias, puseram em xeque não só a capacidade da administração desse tipo de racionalidade técnica-instrumental (como pensou a teoria crítica de Frankfurt, mesmo com um pessimismo diante dela), mas qualquer forma de racionalidade que possibilite pensar o social sob a forma de totalidade, dando conexão aos fatos históricos e às esferas da sociedade (como pensou o movimento pós-metafísico). A noção de totalidade parecia, para os “novos críticos da razão”, exercer uma força terrorista sobre o conjunto dos demais discursos, na medida em que, ao integrar todos os componentes sob sua lógica, favorecia o desenvolvimento do 
pensamento ortodoxo e mesmo fanático em termos de ideologia, política e lógica social ${ }^{3}$.

Assim, o pós-modernismo é um movimento difícil de precisar, só podendo ser definido pelo que rejeita. Para fins didáticos, identificamos quatro pontos principais de crítica em relação ao pensamento moderno: primeiro e novamente, uma voraz rejeição à categoria analítica de totalidade, na medida em que não é mais a síntese e a integração dos diversos aspectos da realidade, mas os fragmentos históricos que se tornam o centro das análises dos fenômenos; segue-se, em segundo, uma crítica à concepção teleológica da história (existência de um telos unificador dos fenômenos) e à noção de que seja possível chegar a uma explicação, mesmo que provisória, sobre as origens, causas, tendências e sobre os elementos constitutivos fundamentais dos fenômenos históricos; em terceiro, uma crítica radical à articulação entre história e utopia, em um ceticismo que não concebe, nos projetos coletivos de sociedade, qualquer futuro além de um "presente eterno"; e por fim, uma crítica epistemológica ao processo de criação de conceitos que, até então, eram elementos constitutivos indiscutíveis dessa ciência e que agora são qualificados pelos pós-modernos de “abstrações sociológicas”, cedendo lugar a "métodos de decodificação" (como os jogos de linguagem) que só permitem uma análise de contextos específicos e fragmentados, com vistas a uma "operatividade".

Neste sentido é que se pode dizer que somente a partir de rejeições e rupturas, fugindo de qualquer sistematização e definição acerca de aspectos da realidade social, é que podemos reconstituir o fio único que perpassa os princípios pós-modernos: a ênfase na natureza fragmentada do mundo e do conhecimento humano - princípios que modificam substancialmente a capacidade de uma análise realmente histórica da realidade social e de seus processos de mudança. Distanciam-se assim da discussão sobre a causalidade na história (ora no conflito de classes, ora na racionalidade humana) argumentando-se que a própria razão é

Não é à toa a irresponsável ligação feita, por estes teóricos, entre o hegelianismo e o projeto nazista alemão. 
vulnerável ao questionamento e que tudo que nos resta é o recorrer à linguagem: "o discurso é tudo" e, acreditem, "tudo é o discurso".

Visualiza-se um mundo contingente, diverso e instável, repleto de interpretações desunificadas, gerando um certo grau de ceticismo em relação à objetividade da história e à estabilidade das normas e dos valores sociais. A reprodução das estruturas sociais depende da cognitividade dos agentes no tempo e no espaço, processo mais dinâmico do que aquele suposto pela regência de leis universais e regulares. As estruturas sociais foram abaladas, e as referências estabelecidas tornam-se cada vez mais tênues. Há uma insistente rejeição à idéia de que as formas sociais podem ser explicadas mediante a referência a forças ou pressões que saturam e modelam a ordem social, mesmo que estes determinantes sejam historicamente específicos.

Conceitos como alienação, reificação ou ideologia devem ser evitados nas análises, pois, para os pós-modernos, nestas noções, são traçadas linhas divisórias entre aquilo que, em um discurso, inclui-se na categoria de verdade, e aquilo que se encaixa em uma outra categoria (como um discurso ocultador, mascarador ou ideológico). Não há qualquer possibilidade de se trabalhar com esses conceitos (ou com quaisquer que seja), pois nossa existência “pós-moderna” está imersa em incontáveis efeitos perdidos e pontos de referências altamente instáveis, que não permitem mais o encontro de parâmetros para analisar qualitativamente as ações e interpretações humanas.

Grande parte do pensamento pós-moderno encontra o sentido das formas sociais não em relações, mas na diferenciação. Separados de quaisquer determinantes sociais, os fenômenos deixam de ser vistos como resultados de relações historicamente dadas, tornando-se aspectos eternos e naturais da sociedade contemporânea. Cai-se justamente naquilo que se deseja rejeitar: o "essencialismo". Pois, o combate ao chamado “essencialismo moderno" é feito reduzindo o social a um agregado de individualidades, elaborados a partir do imperativo do discurso, que termina por negar completamente as reais determinações sociais e voltar novamente à naturalização dos fenômenos sociais. "A diferença e a individualidade discursiva torna-se o absoluto da história” (MALIK, Kenan, 1999), e é irônico como este determinante acaba desempenhando o mes- 
mo papel essencialista que os fatos naturais representavam no empirismo do século XIX.

Essa rejeição à totalidade também recorre a certos princípios epistemológicos articulados de forma confusa e ilógica. O mais sério deles é a noção de que os fatos sociais não podem ser tratados sem a mediação dos valores e concepções intrínsecos ao observador. Claro, isso é bastante óbvio, mas, a partir deste postulado kantiano, é deduzido o absurdo de que não existam nexos causais objetivos a serem sistematizados pelos observadores. "Eles aproveitaram a multiplicidade dos significados para rejeitar não só padrões comuns de juízos de valor, mas qualquer possibilidade de comensurabilidade entre os diferentes mundos de significados" (MALIK, Kenan, 1999).

Estes aspectos de rejeição e princípios epistemológicos são vistos de maneira bastante peculiar em cada autor deste movimento, sendo bastante difícil contemplar todas as características e adeptos (declarados ou não) desta vertente tão ampla. A fim de enriquecer nossa discussão, arriscaremos expor, superficialmente, de que forma estes princípios pósmodernos (antitotalidade, antiteleologia, antiutopia e tantas outras contraposições) são articulados por dois autores específicos e com bastante visibilidade do movimento intelectual pós-moderno. Jean-François Lyotard e Jean Baudrillard são os dois autores discutidos, e é interessante ver como eles, a partir de princípios bastante semelhantes, divergem na recepção e emprego destes: transitam entre uma fragmentação da realidade social do indivíduo na textualidade, festejada como a preponderância da eficiência e da performance sobre o metadiscurso (como em Lyortard); e entre um pessimismo com ares trágicos diante da preponderância do fictício e da simulação sobre a materialidade e a estabilidade do real (como em Baudrillard).

\section{Lyotard e o fim das metanarrativas}

As grandes narrações da modernidade (Iluminismo, Idealismo, Marxismo), para Lyortard, tiveram seu crepúsculo graças a uma espécie de “autodeslegitimação” por parte das próprias narrativas, que aspiravam a 
um saber globalizante, capaz de reconhecer os vários setores do conhecimento e da linguagem. Segundo ele, esses setores são definitivamente incomensuráveis. Não existe, de fato, uma metalinguagem geral, na qual todas as outras linguagens possam se manifestar. A sociedade pós-industrial assinala o declínio das grandes narrativas unificadoras da modernidade, e o pós-modernismo é definido pela incredulidade em relação a elas:

A função da narrativa perde seus atores, os grandes heróis, os grandes perigos, os grandes périplos, e o grande objetivo. Ela se dispersa em nuvens de elementos narrativos, mas também denotativos, prescritivos, descritivos, etc. cada um veiculando validades pragmáticas sui generis.

Para Lyortard, nasce uma sociedade que se baseia menos em uma "antropologia newtoniana" (como o estruturalismo e a teoria dos sistemas) e mais em uma "pragmática das partículas de linguagem”. Como resultado dessa situação, o próprio poder organizador da ciência tende a se enfraquecer, e seu campo a diluir-se em crescentes especialismos, cada qual com seu modo particular de proceder, o que Lyotard chama de "jogos de linguagem” (Lyotard,1993). Esses jogos de linguagem não recorrem a nenhum princípio externo de justiça ou de autoridade, e podemos observar na sua estrutura de funcionamento que não consideram a existência de uma metalinguagem geral. O objetivo do conhecimento científico e seu princípio de legitimidade não são mais a busca da verdade, mas da performatividade, ou seja, a questão não é mais “o que é?”, mas “para que serve?”. O critério de desempenho surge, portanto, como o novo dispositivo de legitimação:

...o desempenho, aumentando a capacidade de administrar a prova, aumenta a de ter razão,(...), as chances de que uma ordem seja considerada como justa aumentariam com as chances dela ser executada, e estas com o desempenho do prescritor.,(...), o "controle do contexto", isto é a melhoria das performances realizadas contra os parceiros que constituem este último (seja a natureza ou os homens) poderia valer como uma espécie de legitimação. Seria uma legitimação pelo fato. (Lyotard, 1993, pg.84) 
No bojo dessa disseminação dos jogos de linguagem parece que encontramos um certo tipo de dissolução do sujeito social, já que o vínculo social é fortemente de linguagem, e assistimos a uma multiplicação de jogos de linguagem que obedecem a regras de diferentes contextos (Lyotard, 1988: 73). Contudo, apesar do vínculo social ser lingüístico, não é tecido por um fio único, mas por um número indeterminado de jogos de linguagens. Cada um de nós vive na intersecção de muitos desses jogos de linguagem, segundo Lyortard, sem a preocupação de estabelecer relações lingüísticas estáveis (Harvey, 1998).

A sociedade pós-moderna compreende, portanto, uma multiplicidade de jogos diferentes e incompatíveis, cada qual com seus próprios princípios intransferíveis de autolegitimação, o que aponta para a passagem do domínio das grandes narrativas para a autonomia fragmentadora das micro-narrativas. Segundo Lyotard, se por um lado teremos que enfrentar a dificuldade de que nesse estado de coisas parece não haver como regulamentar a ciência em nome de projetos utópicos - ideologias ou cosmovisões ligadas a projetos políticos - não sendo possível, por conseguinte, a universidade e outras instituições de pesquisa e ensino ocuparem-se apenas com a transmissão e produção de conhecimento científico, e sim de construir uma atuação cada vez mais submetida ao princípio da performatividade. Por outro, libertamo-nos do imperialismo cultural das metanarrativas, acolhendo e promovendo toda forma de diversidade cultural, sem recorrer a princípios universais.

O abandono das narrativas centralizadoras é visto por Lyotard de maneira positiva, já que significa a possibilidade feliz de proliferação de múltiplos jogos de linguagem, que não devem ser organizados em consenso ou diálogo de subjetividades. O dissenso, entre eles, é a condição mesma da invenção, e sua diversidade produz uma prática científica que torna nossa sensibilidade à diferença mais aguçada e reforça nossa capacidade de tolerar os limites da ciência. Assim como o discurso de verdade, o consenso, enquanto critério de validação, também é insuficiente, pois ele é nada mais que "um horizonte, jamais poderá ser atingido" (Lyotard, 1993).

Dessa forma, como o saber não é só o momento do consenso, mas o do dissenso, do paralogismo, faz-se necessário, para o pós-moderno, 
reconhecer o "heteromorfismo contra um isomorfismo globalizante que, no plano concreto, pode ser traduzido em violência ou totalitarismo" (LYORTARD, 1993). Chegou-se ao saber pós-moderno somente por meio de uma forma de pensar que visa a legitimações fluidas, parciais e, se necessário, reversíveis, distantes de uma razão forte de tipo epistêmico.

Para Lyortard, orientar o problema da legitimação da ciência no sentido da busca de um consenso universal, como o faz Habermas (por meio de diálogos argumentativos ou diskurs), não faz qualquer sentido, sendo até de certa forma suspeito. Seria atribuir um caráter homogêneo aos jogos de linguagem, destituindo-os de sua grande "conveniência": a flexibilidade de suas formas e regras pragmáticas constitutivas. A única forma de consenso possível será, renunciando à "isomorfia terrorista habermasiana”, o consenso sobre as regras que definem cada jogo de linguagem. Esse consenso é, portanto, local, instantâneo e efêmero, sempre sujeito a eventuais anulações: são "contratos temporários" entre os indivíduos, favorecidos pelo sistema por causa de seu menor custo e por sua operatividade. Esta concepção contratualista tem como única meta a assunção pelos indivíduos das responsabilidades sobre as regras dos jogos de linguagem e de seus efeitos, e com isso, o reconhecimento de sua parcialidade e instabilidade. Portanto, em oposição a Habermas: "o consenso é um estado de permanentes discussões, não o seu fim”. (Lyotard, 1993, pg. 118)

Resta-nos dizer que os jogos de linguagem, ao "aguçar nossa capacidade de suportar o incomensurável", ou seja, de se ter um conhecimento mais abrangente dos fatos, como defende Lyortard, é um recurso metodológico que não pode ser conciliado com uma análise realmente histórica dos fenômenos sociais. As relações são enfocadas em seu aspecto “agonístico", e o homem é confrontado por uma encruzilhada de relacionamentos pragmáticos e estratégicos, vistos de forma autônoma e isolada, na medida em que a coerção social nada mais é do que um mero obstáculo, dentre tantos, que impõe alguns limites aos jogos de linguagem. Uma "atomização do social” em flexíveis redes de jogos de linguagem não nos permite ir além de um microrrelato contextual a ser dissolvido pelo próximo "golpe" (um novo enunciado, nos termos de Lyortard). A concepção de uma história que forme um conjunto que ordene o com- 
posto desses relatos não faz qualquer sentido... Mas tudo em nome da eficácia e da potência humana, é claro.

\section{O “vazio do real" em Jean Baudrillard}

Baudrillard procura focalizar a pós-modernidade sob o ponto de vista da proliferação da imagem-signo, observando-a como um tipo de mercadoria cada vez mais hegemônica nessa nova conjuntura. A "formasigno" se apossa da materialidade da produção e do trabalho para eliminar toda a sua significação histórica, absorvendo-o no processo de sua própria reprodução: "o trabalho, esvaziado de sua energia e substância, ressuscita como modelo de simulação de social...”. É como se a única função do signo fosse reproduzir a si mesmo, sem a ilusão de designar algum aspecto da realidade. De acordo com o ponto de vista de Baudrillard, uma inflação de signos que colocaria em xeque a própria distinção entre realidade e ficção é um dos elementos que compõem o quadro das sociedades ocidentais contemporâneas. A pós-modernidade, segundo Baudrillard, é uma época em que não existe mais a preocupação de que os signos tenham algum contato verificável com o mundo que representam, o que ele chama de domínio do simulacro. Foi possível substituir o real por uma versão que, não tendo lastro no real, produz, pelo mecanismo dos universais abstratos, um efeito eficaz de realidade:

...todos os signos se trocam doravante entre si sem nenhuma troca com
o real (e eles só se trocam entre si sob a condição de não mais se trocarem
com o real). Emancipação do signo: liberado dessa obrigação "arcaica"
de ter que designar alguma coisa, ele se torna enfim livre para um jogo
estrutural, ou combinatório, de acordo com uma indiferença e uma
indeterminação totais que sucedem à regra anterior de equivalência de-
terminada. (Baudrillard, 1996 p.16)

Refletindo a respeito das possíveis interpretações da conjuntura recente a partir da contribuição teórica de Marx (em uma interpretação de má vontade), Baudrillard elabora uma "reinterpretação", bem ao seu 
modo, de suas previsões referentes ao desenvolvimento do capitalismo, terminando por sugerir um alargamento crítico da noção de valor, a chamada "revolução estrutural do valor". Seriam três os estágios do crescimento do mercado e do seu elemento identificador, o valor de troca, quais sejam: numa primeira fase, somente uma pequena proporção do que é produzido nas oficinas, na agricultura ou outro setor de produção é utilizado para a venda ou troca no mercado (contrafação); num segundo momento, tudo o que é produzido pelas revolucionárias formas industriais de produção se torna em mercadoria para venda / troca no mercado (produção); na terceira fase, qualidades abstratas - como sentimentos, o conhecimento - também começam a fazer parte do domínio do valor de troca (simulação).

A “era da simulação", estágio contemporâneo, é caracterizada por um aspecto de extrema comutabilidade de termos, instituições e valores outrora contraditórios: o "feio" e o "belo" na indústria da moda, "esquerda" e "direita" na política, "verdadeiro" e "falso" nas mensagens da mídia, "utilidade" e "inutilidade" ao nível dos objetos, "natureza" e "cultura", etc. Todos os grandes julgamentos morais, estéticos ou práticos se diluem neste sistema de "domínio do código", pois em toda a sociedade repousa o princípio da neutralização e da indiferença. Conceitos como classe, estado ou poder são considerados por Baudrillard como mistificações vazias, na medida em que suas representações, dentro mesmo das ciências sociais, esforçam-se por mascarar a existência de um vazio - o vazio do social - através de, por exemplo, realização de pesquisas de opinião pública, consultas pela TV e outras estratégias dos cientistas sociais para elaborar um desenho, um perfil da massa silenciosa, opaca e amorfa. A idéia de "massa" não seria, na verdade, passível de conceitualização sistemática (se é que isso é possível para ele), é uma espécie de "força de absorção e neutralização" que desubstancializa e desfaz qualquer referência dos signos:

A massa absorve toda energia do social, mas não a refrata mais, absorve todos os signos e todos os sentidos, mas não os repercute. Absorve todos as mensagens e as digere. Ela dá a todas as questões que lhe são postas uma resposta tautológica e circular, (...). Todo mundo a interroga, 
mas nunca enquanto silêncio, sempre para fazê-la falar. Ora, a força de inércia da massa é insondável: literalmente nenhuma sondagem a fará aparecer, pois ela existe para eclipsá-la. (Baudrillard, 1985 pg.)

Para explicar o processo pelo qual a representação vai gradualmente perdendo o contato com o real, Baudrillard, a partir dos estágios de estruturação do valor, elaborou também uma sinopse dos quatro estágios pelos quais teriam passado os signos: inicialmente, o signo é o reflexo de uma realidade básica; no segundo estágio, o signo "mascara e perverte uma realidade básica”; no terceiro estágio, o signo "mascara a ausência de uma realidade básica”; no estágio terminal, o quarto, ele é seu próprio simulacro. A simulação toma, na pós-modernidade, a forma de objetos e experiências que se pretendem mais reais do que a própria realidade, o que caracteriza, para o autor, o fenômeno da produção da hiper-realidade.

As transformações ocorridas do segundo para o terceiro estágio foram muito maiores que a compreensão do velho Marx (agora mais velho do que nunca) e de muitos de seus seguidores. Diz Baudrillard que naquela transição já não era possível separar os domínios do econômico, do cultural, ou ideológico, porque artefatos culturais, as imagens, as representações e até os sentimentos e estruturas psíquicas tornaram-se parte do econômico:

Tanto na lógica dos signos como na dos símbolos, os objetos deixam totalmente de estar em conexão com qualquer função ou necessidade definida, precisamente porque respondem a outra coisa diferente, seja ela a lógica social, seja a lógica do desejo, as quais servem de campo móvel e inconsciente de significação. (Baudrillard, 1995 p. 11)

A transformação que daria origem à necessidade de revisão da teoria marxista para um efetivo entendimento da conjuntura recente, seria o fato de que, na vida contemporânea, a forma mais desenvolvida de mercadoria não é a de objetos materiais, concretos, e sim, a imagem. Esse dado exigiu de Baudrillard uma revisão fundamental: à subordinação das operações da cultura e da significação à atividade econômica presente no marxismo tradicional, ele contrapôs a idéia de que a esfera cultural 
além de ser autônoma, "invade” a esfera econômica, transformando seu status radicalmente. Em lugar do econômico ser o principal determinante da vida social, a cultura passaria a ser o locus preponderante da moldagem das relações sociais, atuando inclusive sobre o significado dos aspectos econômicos e, por conseguinte, no seu poder de influenciar a dinâmica das sociedades.

O autor acredita que, ao invés de funcionarem como reflexos superficiais das relações sociais em que se fundamentaram, os valores, os produtos da indústria da opinião pública e as significações, em geral, permeiamnas, determinando-as significativamente - o que seria um dos elementos característicos da pós-modernidade. Neste sentido, a mídia e os meios de comunicação não apenas reproduzem ou comunicam o real: eles realmente o constroem autonomamente. $\mathrm{O}$ mundo da simulação faz com que o ilusório, a cópia, a comunicação, não apenas imitem o real, eles tornam-se o real: “os simulacros são cópias que não têm originais ou de originais que foram perdidos. São imagens assassinais do real assassinas de seu próprio modelo”. (Kumar, 1997. p. 134)

Essa concepção está baseada na realidade das sociedades contemporâneas, marcadas pela explosão e aceleração da produção de artefatos culturais e de signos que funcionam como mercadorias e que apontam para a abstração da troca de produtos materiais sob a lei da equivalência geral. Esta, por sua vez, rege a operacionalização de todas as trocas, subordinando-as ao código semiótico unificador que opera na cultura de massas. Uma das propostas de saída desse sistema dominado pela lógica do código dos signos seria, para Baudrillard, a construção de trocas simbólicas espontâneas e radicais, que ocorreriam fora do âmbito dos meios informacionais, passando a personificar os códigos em sua própria forma e negando a resposta ou a troca na comunicação de massa. Segundo o autor, esses meios trabalham no sentido de produzir a não-comunicação, confirmando a mudez do público pela simulação de suas respostas.

O caminho que Baudrillard seguiu para anunciar a impossibilidade de análises históricas dos fenômenos sociais foi bem diferenciado da trajetória de Lyortard: enquanto este último decreta a emergência de um período “pós-histórico” a partir de uma "fundamentação” epistemológica (decadência dos processos de legitimação científica), destacando que 
não há mais necessidade de princípios científicos gerais e consensuais que permitam falar de uma trajetória histórica; Baudrillard o faz a partir de fundamentos essencialmente ontológicos (o processo de desreferenciação e autonomização da linguagem, ou melhor, "o fim do real”). Entretanto, as duas ênfases no "fim da história” tanto a "entusiasta" quanto a "desesperada” terminam por cair em uma única atitude diante da realidade: a de mera contemplação e resignação diante da sociedade e do fluxo da história, como veremos a seguir.

\section{Considerações finais: Conseqüências Políticas da "Pós-história"}

Primeiramente, é importante enfatizar que o pós-moderno (e também a pós-modernidade), para nós, não surgiu como um período histórico específico, uma nova era. Surge antes como uma tendência ou um movimento intelectual que, embora heterogêneo, tem algumas características gerais compartilhadas pelos autores que o integram (mesmo que boa parte negue sua adesão e "militância” no movimento). Talvez a interpretação mais instigante do movimento pós-moderno nos tenha sido dada por Agnes Heller, nas primeiras páginas da Condição política pós-moderna, onde ela situa seus protagonistas em relação à modernidade: "são os que têm problemas com ela e interrogações a ela relativas, são os que fazem um inventário de suas conquistas assim como de seus dilemas não resolvidos”. Logo, para eles, o pós-moderno surge como uma espécie de “parasita da modernidade" que vive de seus problemas e impossibilidades. Esses problemas e interrogações, para autores como Marshall Berman, são características imanentes à própria modernidade, na medida em que a crise seria um dado intrínseco à condição moderna: "Esse sistema requer constante perturbação, distúrbio, agitação, precisa ser permanentemente empurrado e pressionado para manter a própria elasticidade e capacidade de recuperação...” (Berman, M, 1992). Para Berman, movimentos como o "pós-moderno" seriam apenas manifestações do radicalismo e da crítica tipicamente modernos.

Grande parte das leituras mais críticas (e mais lúcidas) acerca do movimento pós-moderno ao se fazer perguntas de natureza histórica so- 
bre origens e fontes, chegou a uma conclusão bastante conhecida: este movimento é um fruto de determinados interesses sociais e políticos e seus objetivos e efeitos são definidos em conformidade com os objetivos tradicionais das elites políticas e econômicas. A autonomização dos setores sociais, em detrimento da visão de totalidade, é um velho recurso conservador de investigação no pensamento social - Marx, em suas discussões com os economistas de sua época, que o diga.

Este é um ponto central na discussão acerca destes teóricos, contudo, gostaríamos de seguir um outro caminho. É importante analisar alguns pontos secundários à primeira vista, mas que nos parecem extremamente determinantes no quadro científico atual. Em primeiro lugar, e já falado anteriormente, o pós-moderno é um movimento intelectual composto, em sua grande maioria, de remanescentes da esquerda política. Os movimentos políticos parisienses do "maio de 68" e a influência do existencialismo e do estruturalismo nestes grupos criaram uma geração desiludida com sua própria concepção de mundo ${ }^{4}$. Os mesmos teóricos que impulsionaram estes grupos políticos fizeram a etremunção dos movimentos sociais ${ }^{5}$. Em segundo lugar, uma coisa é certa: as grandes narrativas políticas da modernidade estão passando por um completo descrédito e estagnação. Isto é um fato, e afirmar isso não é conservadorismo. E mais: o radicalismo do movimento pósmoderno nos alertou para este acontecimento. Este é um mérito indiscutível. O problema é que, do ponto de vista científico, o fim das narrativas foi associado, por estes autores, com a incapacidade analítica dos referenciais teóricos que as alicerçaram, falamos especialmente do materialismo histórico, saco de pancada dos autores pós-modernos. $\mathrm{O}$ declínio da força política do marxismo não pode coincidir com a incapacidade do materialismo histórico de interpretar criticamente a realidade social e, muito menos, com a perda de importância dos objetivos sociais que o fundamentaram. E esta confusão é fruto das próprias ca-

Heller, A, FEHER, F, 1998.

A escola de Frankfurt e sua dialética negativa ilustram bem este desespero. Se bem que foi mal interpretada pelos teóricos posteriores que transformaram, como já dito, a negação da razão instrumental em uma negação de qualquer tipo de racionalidade. 
racterísticas do marxismo: sua luta permanente para a superação da distinção prática/teoria, envolvendo características tanto de produção do conhecimento como de movimento político, não sendo à toa o fato de que seus maiores pontos de transformação e desenvolvimento coincidiram com grandes acontecimentos políticos que tiveram, por diversas vezes, a participação de seus principais autores.

Em terceiro e último lugar, observamos, juntamente com o declínio das narrativas centrais do século XIX e XX, o surgimento de outras narrativas (vimos algumas de suas manifestações no decorrer deste trabalho) de grande impacto político: as narrativas da diferença (relativistas), do ceticismo e da fragmentação, que estão se tornando base não só para a leitura da sociedade contemporânea, mas também para a configuração da agenda política atual. Entretanto, há uma diferença crucial em relação às “falecidas narrativas modernas": seus discursos, em lugar de fornecer uma visão da sociedade enquanto produto histórico, colocam a condição contemporânea como um traço permanente da vida humana na medida em que eliminam a necessidade de se ver como parte de um processo histórico mais geral. E isso vem criando um mal-estar na cena intelectual e política sem precedentes: o mundo nos é mostrado como um "grande texto" que não podemos ler, uma "Matrix” sem oráculo ou heróis humanos, dando margem, desse modo, a um sentimento de impotência humana que acaba coincidindo com os interesses capitalistas contemporâneos, embora advenha de autores da esquerda política européia. Como denúncia desta situação atual, podemos apontar o nascimento de radicalismos políticos e religiosos que, se visto com mais cautela (como o fizeram Castells e Agnes Heller), aparecem como reações extremas a esse vazio "pós-histórico". Nas palavras de Heller: "o novo fundamentalismo é a voz da má consciência da condição pós-moderna, flagelando-se por sua excessiva tolerância com o relativismo”. (1998, p.18).

Ao rejeitar a noção de totalidade - que nos permite ver aspectos comuns e as ligações entre elementos aparentemente heterogêneos e desconectados - o discurso pós-moderno solapa sua própria capacidade de contestar as explicações naturalistas da realidade e, mais do que isso, elimina qualquer possibilidade de auto-reflexão, crítica e superação, procedimentos tão caros à tradição científica desde seus primórdios. 
A história agora é vista ora como derrota, ora como caos. Parece ser impossível não nos depararmos com a angustiante percepção de volta aos primórdios pré-modernos (agora com ares de “pós”): uma sensação de emersão na "imobilidade medieval” que não consegue ter uma visão global dos processos históricos, uma ressacralização que valoriza a dimensão local ou privada, julgadas mais gratificantes ou mais "seguras" diante dos "infortúnios” sociais e políticos contemporâneos.

\section{REFERÊNCIAS BIBLIOGRÁFICAS}

BAUDRILLARD, Jean. À sombra das maiorias silenciosas: o fim do social e o surgimento das massas. São Paulo: Brasiliense. 1993.

BAUDRILLARD, Jean. A troca simbólica e a morte. São Paulo: Loyola, 1996 (partes I e II)

BAUMAN, Zygmunt. O mal-estar da pós-modernidade. Rio de Janeiro: Zahar, 1998.

BERMAN, Marshall. Tudo o que é sólido se desmancha no ar: a aventura da modernidade. São Paulo: companhia das letras, 1992.

BODEI, Remo. A história tem um sentido? Bauru, SP: EDUSC, 2001.

CASTELLS, Manuel. O poder da Identidade (a era da informação: Economia, sociedade e cultura v. II). São Paulo: Paz e terra, 1999.(a política informacional e a crise da democracia)

EAGLETON, Terry. As ilusões do pós-modernismo. Rio de Janeiro: Zahar, 1998.

EVANGELISTA, João Emanuel. “Ascensão” e "Queda” da Modernidade? (mimeo). Natal/são Paulo, 1999.

EVANGELISTA, João Emanuel. "Elementos para uma crítica da cultura pós-moderna”. Revista Novos Rumos. São Paulo: Novos Rumos. V.34 pg. 29-40,2001

HARVEY, David. A condição pós-moderna: uma pesquisa sobre as origens da mudança cultural. São Paulo: Loyola, 1992

HELLER, Agnes e FEHER, F. A condição política pós-moderna, 1998. 
JAMESON, F. "Pós-modernidade e sociedade de consumo". In: Novos Estudos CEBRAP, n. 12. São Paulo, junho de 1985.

KOSIK, K. Dialética do concreto. $7^{\mathrm{a}}$.ed. Rio de Janeiro: paz e terra, 2002.

KUMAR, Krishan. Da sociedade pós-industrial à pós-moderna: novas teorias sobre o mundo contemporâneo. Rio de Janeiro: Zahar, 1997.

LYOTARD, F. O pós-moderno. 4.ed. Rio de Janeiro: José Olimpio, 1993

ROUANET, S. Mal-estar na modernidade: ensaios. São Paulo: Companhia das letras,1993.

SANTOS, Boaventura de Souza. "O social e político na transição pósmoderna". In: Pela mão de Alice: o social e o político na pós-modernidade. São Paulo: Cortez, 1995

WOOD, Ellen e FOSTER, Jonh Bellamy (org.). Em defesa da História: Marxismo e pós-modernismo. Rio de Janeiro: Zahar, 1999. 